\title{
Insights and models from medical anthropology for understanding the healing activity of the His- torical Jesus
}

John J Pilch

Georgetown University, Washington (DC)

\begin{abstract}
This essay sketches a basic introduction to medical anthropology as a key to understanding and interpreting the healing activity of the historical Jesus described in the gospels. It presents select literature, leading experts, fundamental concepts, and insights and models of special value to biblical specialists. Only a cross-cultural discipline like medical anthropology allows the investigator to interpret texts and events from other cultures with respect for their distinctive cultural contexts in order to draw more appropriate conclusions and applications in other cultures. Applications to biblical texts are not included in this essay but may be found in other articles published by the author and listed in the bibliography.
\end{abstract}

\section{INTRODUCTION}

The 'moonstruck' were one category of people Jesus healed (Matt 4:24; 17:15). Plutarch described the effects of moonlight upon human beings in this way:

\begin{abstract}
Nurses are exceedingly careful to avoid exposing young children to the moon, for, being full of moisture like green wood, they are thrown into spasms and convulsions. And we see that those who have gone asleep in the light of the moon are hardly able to rise again, like men with senses stunned or doped, for the moisture poured through them by the moon makes their bodies heavy.
\end{abstract}

(Quaes. Conviv. 658E-F)

Some translators of the gospels render the Greek word for 'moonstruck' by the English word 'epileptic'. This translation is an interpretation that illustrates medicocentrism (Pfifferling), a species of ethnocentrism that chooses to view texts from the ancient 
Middle East about sickness and healing in a Western biomedical perspective. Historians of medicine are as guilty of medicocentrism as exegetes and theologians (Scarborough 1969).

Medical anthropologists would identify the human experience of being 'moonstruck' as a 'culture-bound syndrome' similar to phii pob in rural Thailand (Simons and Hughes 1985:489) or gila babi in rural Malaysia (Simons \& Hughes 1985:481). The sickness that results from the 'evil eye' belongs to this same category (Simons \& Hughes 1985:487; Herzfeld 1986). Since all illness is culturally constructed, a more accurate term would be 'folk conceptualized disorders', but 'culture-bound' is still commonly used. No medical anthropologist identifies such human problems as misconceptions or superstitions.

This essay sketches a basic introduction to medical anthropology for those interested in understanding the healing activity of the historical Jesus respectfully and appropriately in its cultural context. It presents select literature, leading experts, fundamental concepts, and insights and models of particular interest to biblical specialists.

Arthur Kleinman is universally respected as one of the most knowledgeable and influential medical anthropologists who, along with various collaborators, has shaped and contributed to the growth and development of the field. By reading just the work he has authored (e g 1988), co-authored (e g Csordas and Kleinman; Hahn and Kleinman), or edited (Eisenberg and Kleinman), a researcher can learn the entire field in all its complexity.

For those interested in a broader grasp of medical anthropology, Wellin surveys the five or six decades of research leading up to 1978 and highlights the major conceptual models.

The extensive bibliography in Johnson and Sargent (1990) can serve as a master list for additional references on any topic mentioned in this essay. It can be supplemented with the resource lists in Hill (1985) and Logan and Hunt (1978).

\section{SITUATING THE DISCIPLINE}

Medical anthropology is one of five subdisciplines of anthropology (McElroy and Townsend 13-17):

* Physical anthropology, also called biological anthropology or human biology, is the study of the physical origins and variations of the human species. The study of origins focuses on the fossil record and on the behavior of living nonhuman primates. Investigation of variations compares contemporary human groups on the basis of skin color, blood type, hair form, bone structure, and stature. Subdisciplines include: anthropometry or surface measurements; biomedical anthropology: growth and nutrition; health and physique; disease. 
* Prehistoric archaeology works without benefit of documents such as those used by classical archaeology. It focuses on artifacts and other material remains, including skeletons. This subdiscipline demonstrates how health, culture, and environment are related.

* Anthropological linguistics, also called sociolinguistics, analyzes sound systems and grammars. Its contribution to medical anthropology is the methodology calied ethnobioscience or ethnosemantics that seeks to learn how participants in a given culture categorize their experience. Such research helps construct 'semantic illness networks' (Good 1977; Good and Good 1981) that highlight the culturally significant categories natives or insiders use to describe a human condition of misfortune called sickness. Technically, this is called the 'emic' perspective.

* Cultural Anthropology studies the way of life that a particular group of people follows. Foster and Anderson (1978) identify three roots of medical anthropology in the earlier work of cultural anthropology: studies of witchcraft, magic and primitive medicine; studies of personality and mental health in diverse cultures; and, particularly after World War II, studies in international public health.

Of special interest to Historical Jesus research is the sub-discipline of Mediterranean anthropology, which provides medical anthropology with knowledge about distinctive cultural values, beliefs, and behaviors that illuminate the understanding of health, sickness, and healing in the circum-Mediterranean area (Gilmore 1982; Murdock 1980; Gaines and Farmer 1986; Harwood 1981; Henderson 1989; Henderson and Primeaux 1981; McGoldrick et al 1982; Palgi 1983; Saunders 1954; Spiegel 1982).

* Medical anthropology currently is one of the most highly developed areas of anthropology, benefiting from the knowledge base already provided by other subdisciplines. Those who seek to dissociate this discipline further from scientific Western medicine prefer to call the field Ethnomedicine (Seymour-Smith 1986:187; Hughes 1968), but medical anthropologists prefer to reserve this term for the study of healing rituals.

One of the aims of medical anthropology is to disentangle 'the closely interwoven natural-environmental, human-biological, and socio-cultural threads forming the behavioral and conceptual network of human responses to the experience of illness' (Unschuld 1988:179). To this end, medical anthropology has developed its own methodological and topicai specialties. A sample is presented in Table 1: 
Table 1: Subfields and Specialities of Medical Anthropology (McElroy and Townsend 1989:17)

\begin{tabular}{|c|c|c|}
\hline $\begin{array}{l}\text { Biomedical Studies of } \\
\text { Adaptation }\end{array}$ & $\begin{array}{l}\text { Ethnomedical Studies } \\
\text { of Health and Healing }\end{array}$ & $\begin{array}{l}\text { Social Problems and } \\
\text { Interventions }\end{array}$ \\
\hline genetics and disease & $\begin{array}{l}\text { culture-bound } \\
\text { syndromes }\end{array}$ & mental health \\
\hline medical ecology & folk therapies & clinical anthropology \\
\hline evolution of diseases & healing roles & addiction \\
\hline social epidemiology & medical pluralism & farinily violence \\
\hline nutrition & ethnopharmacology & birthing studies \\
\hline demography & ethnoscience & disabilities \\
\hline paleopathology & midwifery & public health. \\
\hline
\end{tabular}

The columns in this table should be read vertically; there is no horizontal correlation. Each column identifies a subfield and approach in medical anthropology, under which are listed topical specialities. The research results and insights produced by each subfield make medical anthropology a particularly rich science.

\section{MEDICAL ANTHROPOLOGY'S CHALLENGE}

Biomedicine is as much ideology as science (Kleinman 1980:301). It is guided by Western cultural assumptions and is thoroughly permeated with a particular theoretical and value orientation (Kleinman 1980:18).

Biomedical specialists tend to ignore the sick person's account of the experience and prefer to rely on laboratory tests for the 'truth'. This approach has no means for taking into serious account alternative therapies offered by other healing systems (ancient; primitive; traditional non-Western; folk; popular; modern; Kleinman 1980: $18,28)$.

Medical anthropology grew out of the spread of Western medicine to other cultures, especially after World War II (Whyte, in Van der Geest and Whyte 1988:10). The encounter highlighted just how deeply biomedicine is afflicted with ethnocentrism and biomedical reductionism. Critics believe that this posture continues to be the conventional wisdom of that profession.

One must ask why a discipline whose roots are so deeply planted in Western culture, whose major figures are almost entirely European and North American, and whose data base is largely limited to the mainstream population in Western societies, 
should regard cross-cultural research among the more than 80 percent of the world's people who inhabit non-Western societies as marginal (Kleinman 1988: xi-xii)?

Kleinman's observations on biomedicine, echoed by most if not all medical anthropologists (see Worsley 1982), propose an analogous challenge for biblical studies as well. Why are cross-cultural, social-scientific approaches to studying the ancient Mediterranean world so strenuously resisted by European and North American researchers?

\section{MEDICAL ANTHROPOLOGY'S FRESH APPROACH}

Kleinman (1988) lists three ways to investigate and write about sickness and healing across cultures:

* Borrow concepts originally intended to study other domains of human experience and use them to describe health-care beliefs and practices. Thus results from anthropological investigations of witchcraft, magic, symbol, and the like can be transferred to human health questions. This is a useful method in structurally simple, kinship-based societies, particularly if they are anti-introspective. The body is a 'black box', so people concentrate instead on the social and symbolic conditions of sickness.

* Borrow concepts from medical sociology (Turner 1980). This works best in research on industrial societies but, like sociology, it is not very helpful for studying pre-industrial societies (Fabrega 1971).

* Develop an evolving conceptual system centered on the social and experiential peculiarities of sickness and healing. There are two equally important elements in healing: efficacy (see below) and meaning. Biomedicine focuses exclusively on efficacy, especially as viewed in a narrow biomedical perspective. The ordinary human person is interested in an outcome, but the most important outcome frequently is restoration of lost meaning or discovery of new meaning in life. Medical anthropology is particularly interested in meaning or a hermeneutic dimension of healing.

Medical anthropology has elected this latter method as the most appropriate for its interests. Its practitioners prefer to develop and advance its own ethnomedical paradigm as an alternative to the biomedical paradigm. The science needs an autonomous theoretical frame that is more suitable than any other for describing and interpreting the human experience of health, sickness, and healing (Kleinman 1980:377). 


\section{IMPORTANCE OF MEDICAL ANTHROPOLOGY}

The researcher who has devoted a career to studying the historical Jesus should be encouraged to look to other, supplementary methodologies by this comment from Simons and Hughes 1985:29) in the study of culture-bound syndromes:

[T] he approach advocated here is problem centered rather than discipline centered. Too often discipline-centered approaches have included subtle and sometimes not so subtle attempts to restrict relevances to Those in which I am Certified Expert (or, more charitably, to Those I am Competent to Discuss). In reality, relevant data may lie within many disciplines. And these data can seldom be organized hierarchically. Every set of human behaviors exists in a complex matrix of biological, social, psychological, and cultural facts which shape each other.

How any portion of this set of facts shapes specific aspects of behavior or experience is a matter which must be discovered empirically, and an accurate analogy is not a layer cake but a marble cake.

Interdisciplinary specialists point out that the best interdisciplinary co-operation is often that carried out in the mind of a single researcher, an expert in one field who borrows eclectically from other disciplines and creatively integrates the insights.

\section{SOME BASIC TERMS AND DEFINITIONS}

Kleinman's (1980; Kleinman et al 1978) definitions are generally and widely shared in medical anthropology (Caplan 1981 et al; Cassell 1976; Eisenberg 1977; Engelhardt 1981, 1986; Fitzpatrick 1984; Landy 1977; Ohnuki-Tierney 1981) even if sometimes modified (Young 1982):

\footnotetext{
Health is very difficult to define. It is never clear what is lost when one has lost 'good health'. In general, any definition of health is a descriptive and often culturally normative concept that plays a defining role in a given society.
}

In the United States where a major cultural value is achievement and self-sufficiency, health might be defined as 'the ability to perform those functions which allow the organism to maintain itself, all other things being equal, in the range of activity open to 
most other members of the species (e.g., within two standard deviations from the norm) and which are conducive toward the maintenance of its species' (Engelhardt 1981:32).

The classic definition offered by the World Health Organization, that of a 'state of complete physical, mental, and social well-being and not merely the absence of disease and infirmity', is routinely challenged by Western specialists because of its focus on nealth as a 'state'. Non-Western populations, however, find the definition very meaningful since their cultural values place a high priority on well-being from a variety of perspectives.

Thus, from a general, medical anthropological perspective, health is best understood as a condition of well-being proposed as such by a given culture. Sickness is a blanket term used to label real human experiences of disease and/or illness. This is the proper domain of medical anthropology, though special attention is paid mainly to illness (Twaddle 1981).

Disease is not a reality but rather an explanatory concept that describes abnormalities in the structure and/or the function of human organs and organ systems. This includes pathological states even if they are not culturally recognized (Foster 1976). Disease is the arena of biomedicine and the biomedical model (Kleinman 1980; Grmek 1989; Lipowski 1969).

The concept of disease attempts to correlate constellations of signs and symptoms for the purpose of explanation, prediction and control (Engelhardt 1981:39). The biomedical jargon for these strategies is diagnosis, prognosis, and therapy, and these concepts lead into the field of power and politics (Glick 1967; Pilch 1991a, 1992a, 1992b).

Illness, too, is not a reality but an explanatory concept that describes the human perception, experience, and interpretation of certain socially disvalued staies including but not limited to disease (see Worsley 1982:327). Illness is both a personal and social reality and therefore in large part a cultural construct (Kleinman 1974b; Lewis 1981). Culture dictates what to perceive, value, express, and then how to live illness (Kleinman 1980:417-418; Ohnuki-Tierney 1981, 1984; Weidman 1988; Kaplan 1983). Curing is the anticipated outcome relative to disease, that it, the attempt is made to take effective control of disordered biological and/or psychological processes.

Healing is directed toward illness - that is, the attempt is made to provide personal and social meaning for the life problems created by sickness. Treatment, of course, can be concerned with one or the other aspect of a human problem (disease or illness), and either or both can be successfully treated. The complaint against modern bio-medicine is that it is concerned only with 'curing the disease' while the patient is searching for 'healing of the illness'. This dichotomy separates what nearly all human 
societies view as essential in healing - that is, some combination of symptom reduction along with other behavior or physical transformation that reflects that society's understanding of health and the provision of new or renewed meaning in life for the sick person (Etkin 1988:300).

Healing is an elemental social function and experience. It is equally as basic and fundamental as the gift or the exchange relationship. Healing is one of the primary forms of symbolic action (Kleinman 1974a:210).

These definitions and their implications offer historical Jesus researchers a fresh perspective on sickness and healing in the first-century, Eastern Meditenanean world and a welcome rescue from the tyranny of Western biomedical perspectives.

\section{THE HEALTH CARE SYSTEM}

In every society, the health care system (Mackintosh 1978) is created by a collective view and shared pattern of usage that operates at a local level and is seen and used somewhat differently by different social groups and individuals (Kleinman 1980:39). Thus the health care system is a concept, and not an entity. It is a conceptual model held by the researcher. Kleinman constructed a structural model of a health care system (see Figure 1) that he suggested could be used be used to analyze the system in any society or culture (Pilch 1985).

Figure 1: The Health Care System (after Kleinman 1980:50; Pilch 1985:144)

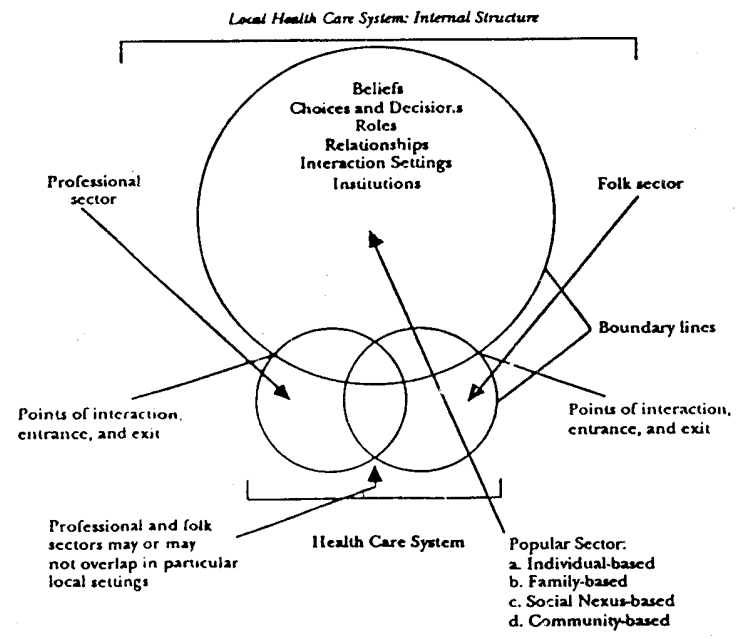

ISSN 0259-9422 = HTS 51/2 (1995) 
Because the whole system heals, not just the healer (Kleinman 1980:72), the investigator needs to conduct both a micro and a macro analysis to see how small-scale events within the healing system in its three sectors might relate to large-scale social structure and processes. Consider the element of power. Glick (1967) proposed that knowing a culture's chief source(s) of power, whether political, social, mythological or religious, technological, will allow the researcher to deduce the beliefs about the causes of illness and how to treat it. Social reality determines what the power is: witchcraft, exorcism, fortune-telling, surgery, psychotherapy, and symbolic reality lay down the pathways by which the application of power may be effective (see symbolic healing below). In turn, political, socio-economic, and cultural power determine which view prevails and which outcomes are acceptable. What insight does this offer into the arguments about the source and legitimacy of Jesus' power to heal?

Finally, Kleinman (1980:415) cautions that health care systems are nearly impossible to understand once they are removed from their cultural contexts. All the greater reason for seeking to discover as much about cultural beliefs, values, and behaviors as possible.

\section{FIVE MAJOR FUNCTIONS OF HEALTH CARE SYSTEMS}

Five elements working together in a given system construct and define both health and illness (Kleinman 1978:416-471). These elements are also called the 'core clinical functions'. In this phrase the word 'clinical' represents 'general health care'.

* Cultural hierarchies of health values. Societies construct a hierarchy of health values, and 'in small scale, pre-literate societies, as well as in many historical cultures, the fit between health values (needs, expectations, choices and evaluations) and healing (therapeutic approaches and outcomes) can often be very tight' (Kleinman 1978:417). This is so because the individual internalizes these health values during the socialization process.

The semantic illness networks (see Good and Good 1981) of given societies tend to cluster a variety of values, concepts, and experience. The West seems to prefer metaphors of war: germs 'invade', the threatened person 'fights' infection, bio-medical researchers 'wage war' against viruses, et cetera. On the other hand, the Taiwanese, among whom Kleinman has conducted extensive research, talk about being 'hit' by ghosts, either purposefully or inadvertently, and thereby becoming ill.

In the Mediterranean cultural world, one must attend to the core values of honor and shame, gender-based division of society, client and patron, sheep and 
goats (Pilch 1992a, 1992b; Murdock 1980), belief in spirits (Saler 1977), attitudes toward pain (Zborowski 1952; Zola 1966) and many other concepts and values that comprise that distinctive cultural hierarchy of health values.

* Experience of illness. Culture dictates what to perceive, value, express, and how to live illness. Culture also plays a significant role in symptom formation (Pilch 1988b), as well as the various psychophysiological processes in and reactions to illness. Culture's greatest contribution is the meaning given to the illness experience. This is also the first stage of healing because the experience can be acknowledged and recognized as something specific which charts the initial path toward an appropriate response.

* Cognitive response: ordering illness by means of labelling, classifying, and explaining. Culture establishes general criteria to guide the therapeutic process and to evaluate the outcomes. This involves creating structures of relevance: is this experience major or minor, important or negligible? The response involves knowing the hierarchies of resort: family, friends, the village, the herbalist, the prophet, the 'professional', et cetera (Pilisuk and Parks 1986; Romanucci-Ross 1969).

Mary Douglas has convincingly demonstrated that illness and its consequences are intensely social and communal events. They are disruptive and often threaten the most essential values, behavioral norms, and conceptions of order. What is required is a restoration of order by placing the threat in its proper framework, by controlling the disruptive effect on the sick person and that person's network, and by making the entire experience personally and socially meaningfull.

To explore this dimension further, one needs to investigate 'explanatory models' (see below) which differ from sick person to sick person, and also between the sick person and the therapist. The cognitive response to misfortune or sickness forms the core of 'symbolic healing' (see below).

* Healing Activities. In actual fact, healing goes on throughout the entire system and in each of these five functions, so one must consider individual healing practices within the total context of the system and indeed of society. In other words, healing entails much more than demonstrable empirical efficacy, important as this may be when or whether it actually occurs (Frank 1974).

Strategies include healing and preventive activities per se which range from empirical remedies (see Van der Geest et al 1988) and technological interventions to symbolic therapies like the placebo (Moerman 1983; see also Dow 1986). 
* Potential outcomes: managing cure or treatment failure, recurrence or chronic illness, permanent impairment, and death. Anthropologists note that much of 'traditional' health care is dedicated to preparing for death and making the experience of dying meaningful. It is especially at this point that health care often overlaps with religion and other cultural systems. In the entire process, of course, constructing a meaningful life is qually important. In this stage, human efforts are focused on answering the question: 'Now what'?

These five functions provide a fairly comprehensive basis for understanding healing and health care in any given culture and allow for more appropriate cross-cultural comparisons. All attempts to understand illness and treatment can be thought of as explanatory models.

\section{EXPLANATORY MODELS (EMs)}

'EMs' are more or less formally structured and coherent accounts of reality - in this case the reality of illness and its treatment. They may be and often are ambiguous and changing and may even contain contradictions and varying degrees of logical development. Social scientists note that all people have multiple belief systems to which they turn when they need help.

EMs are the notions about an episode of sickness and its treatment which are errployed by everyone involved in the process (the sick person, family, friends, village, healers). These models are embedded in the larger cognitive systems which, in turn, are anchored in particular cultural and structural arrangements - that is, the health care system sectors and sub-sectors. Of great import to the medical anthropologist is not only grasping and understanding the EMs but also observing the interaction (see below) between sick persons and healers. This interaction is a central component of health care, and one learns about it by exploring and recording the EMs involved.

Structurally, there are five questions that EMs seek to explain relative to each illness episode (Kleinman 1980:105):

* Etiology - that is, origins and causes;

* Time and onset of symptoms;

* Pathophysiology;

* Course of sickness, including the degree of severity and the type of sick role (acute, chronic, impaired, et cetera);

* Treatment. 
The healer EMs seek to answer all five questions. The family and sick individual EMs usually answer only salient questions. In contrast to professional EMs, those of the lay person ordinarily disclose the significance of a given health problem for the patient and the family, along with their treatment goals.

A review of all the information gathered by the EMs of everyone involved in a given illness episode helps an investigator to realize that efficacy always involves both symptom reduction and restoration of meaning to life.

In practically all of his publications, Kleinman never concludes without suggesting avenues of future research. Here, adapted for historical Jesus specialists, is his list for additional research topics relative to EMs:

- a systematic and holistic study of the local health care system in first-century Palestine, emphasizing interaction between different sectors (professional, lay, folk; public and private; male and female; patron-broker-client, et cetera) and the relation of health-care functions to their component elements;

- a focus on cognitive and communicative aspects of the healer-client relationships, stressing comparisons of and interactions between EMs in the popular, folk, clinical and 'scientific' domains;

- a cross-cultural comparison of psychosocial and psychophysiological aspects of illness experienced in first-century Palestine, emphasizing mechanisms by which culture molds behavior and biology (e g, swaddling socializes an infant to control very early in life; loss of control is permitted in possession or in angry rage after which the person is puzzled and repentant about the uncontrolled behavior just experienced);

- the relationship between meaning (subjective and social) and efficacy in 'traditional' and modern health care;

- a study of local medical systems as adaptive responses to specific stress factors in the physical and social environments (e g, fathers use physical punishment in rearing sons; a son who becomes a violent adult explains violent behavicr through possession by a violent spirit; the violence is tamed by casting out the demon).

\section{TRANSACTION: THE INTERACTION WITH THE HEALER}

While it is the whole system and not just the healer that heals, the transactions between sick people and healers are critical (Mason et al 1969). All transactions between the 
sick person and the healer(s) should be considered fundamentally hermeneutic (Good and Good 1981; Pilch 1988b). What takes place in the interaction is interpretation of symbols and signs in terms of very particular interpretive schemata.

The diverse EMs that all the actors in a healing transaction bring to the event influence the interactions and interpretations that take place. The sick person and the healer are best understood as engaging in the interpretation of the context of the encounter, which itself is symbolic and of the symbolic forms that are manipulated by the other during the encounter. Symbols include words, acts, events, and/or gestures. The healing encounter is recognized as a distinctive kind of encounter, and the specific encounter under consideration is either a new form of interaction, or a repetition of a previously known form of encounter. What the encounter produces is 'understanding' rather than new 'knowledge' or 'explanation' (Gaines 1982:244).

In a recent reflection on these encounters, Kleinman (1988:115-116) constructed another model for comparing healing systems across cultures. The following summary of its key points omits the detail which is understandably required by Kleinman's interest in contemporary industrialized cultures where biomedical systems prevail as well as the traditional cultures he studies in the Far East.

* Setting: folk, popular, professional.

* Characteristics of the interaction

a. Number of participants;

b. Time character: episodic or continuous, brief or lengthy;

c. Quality of relationship: formal or informal, authoritarian or dyadic, et cetera.

* Characteristics of the healer: personality, training, type of practice, insight into the process, et cetera.

* Idioms of communication

a. Mode: somatic, religious, moral, social, et cetera;

b. Code: nonverbal, verbal, special semiotic system;

c. EM of a particular illness episode, e g, shared, conflicting, open, tacit;

d. Rhetorical devices for narratizing illness and negotiating treatment;

e. Interpretation.

* Clinical reality: sacred or secular; disease-oriented or illness-oriented; focus of treatment: sick person, family, et cetera; symbolic and/or instrumental interventions; et cetera. 
* Therapeutic stages and mechanisms: process, mechanisms of change: catharsis, confession, altered state of consciousness, et cetera.

* Extratherapeutic aspects: social control, political implications, et cetera.

Kleinman designed the model specifically for examining symbolic healing systems (e g, forms of religious healing, shamanism, various lay psychotherapies sometimes called ministries). With appropriate modifications and fine tuning, which is standard procedure in the construction and application of models, it can serve well for analyzing healing interactions in the first century world.

\section{SYMBOLIC HEALING}

Medical anthropologists generally agree that religious healing, shamanism, and Western psychotherapy are versions of one and the same thing: symbolic healing (Dow 1986:56; Moerman 1979; Kleinman 1988:131). In symbolic healing, the therapist or healer mediates culture. What is especially important is the metaphorical structure of culture. This is as decisive in effectiveness as any other elements, whether physiological, pharmacological, or anything else. Symbolic healing is best understood by examining the four essential structural processes involved in accomplishing it.

\subsection{Stage 1. Symbolic bridge}

It is important to establish a symbolic bridge between personal experience, social relations, and cultural meanings. Every system of symbolic healing is based on a model of experiential reality that is called the mythic world. If this world does not derive from society's shared meaning, then it derives from initiation into a particular system of healing such as a psychoanalytic relationship or a Catholic charismatic prayer group. The particular cultural mythic world contains knowledge that is experientially but not necessarily empirically true. Together, the healer and the sick person agree to particularize a segment of the cultural mythic world for use in a particular case of symbolic healing (Dow 1986:61).

The mythic world contains the symbols that link the social system to the self system of the sick person. The relationship of these two systems to other systems can be examined in Dow's hierarchy of living systems presented in Table 2. Note the point at which where the symbolic bridge between two systems will occur. 
Table two: Hierarchy of Living Systems (Dow 1986:62)

\begin{tabular}{lll}
\hline Environment & System & Units \\
\hline \hline & & \\
Natural environment & Ecological & Populations \\
Social environment & Social & Individuals \\
Individual environment & Self & Somatic systems \\
Body cells & Somatic molecular & Cells, et cetera \\
& & Molecules (genes).
\end{tabular}

The hierarchy of linked systems in this table is the biopsychocultural basis for healing. For instance, the individual experience (serious loss) is linked with a group's master symbols (the paschal mystery; crucified Christ) which in turn are the deep cultural grammar governing how an individual orients self to others and to the inner world. The cultural grammar is found in the central myths (scripture). Both Dow (1986) and Kleinman suggest the associations noted in parentheses above. Just as illness is expressed at different levels of this hierarchy, so is healing a transformation of these linked systems at various or all levels.

\subsection{Stage 2. Relating the sick person to the mythic world}

A healer activities the symbolic connections for a sick person. The healer persuades the sick person that the problem can be related to some part of the mythic world. For instance, Peter's mother-in-law in the Lucan account suffers from a demon named 'Fever' and therefore she can be treated by exorcism (Pilch 1991a, 1992b). In smallscale pre-literate societies healer, sick person, and the family usually agree about these core meanings.

\subsection{Stage 3. Transactional symbols}

A healer employs mediating (also called transactional) symbols that are particularized from the general meaning system and guides therapeutic change in the sick person's emotional reactions. The focus on emotion in the self system works an effect by way of hierarchical linkage in the somatic system.

It is not just the healer's rhetorical skill at work here. Rather, the participants in symbolic healing share mutual expectations which shape and name the clinical reality - that is, the illness. Then the healer generalizes the personal experience into the therapeutic meaning system, and the sick person particularizes that symbolic meaning into personal experience. 
The sand painting images of Navahc spirits as used with other techniques by Navaho healers are an illustration of such a transactional symbol.

\subsection{Stage 4. Confirmation}

The healer confirms the transformation of the particularized symbolic meaning. Thus, an intrusive spirit, now named, is subjected to specific rituals of exorcism. 'In anthropological terms, the healing interaction fosters this transformation as a work of culture: the making over of psychophysiological process into meaningful experience and the affirmation of success' (Kleinman 1988:134).

Most symbolic healing around the planet takes place in the popular sector - that is, the family and community, and the folk sector (Kleinman 1988:117). Of particular interest is the fact that most healing is not long-term, divorced from every life encounter between participants, psychologically minded, secular, or oriented to the needs and rights of the individual vis-à-vis those of the family and community. The therapeutic relationship is authoritarian in nearly all cultures except the West. This is what one would expect in the sociocentric non-Western cultures as contrasted with egocentric Western culture.

Clearly, interpretation is the core task of healing cross-culturally (Kleinman 1988:119). Non-Western healing systems (Worsley 1982) ordinarily emphasize sacred reality, illness orientation (that is, they take the sick person's account to be the 'real' problem), symbolic intervention, interrogative structure, socio-centric, particularly family-centered locus of control, and rather substantial expectations of change and even cure.

\section{EFFICACY}

'Do (did) real cures really happen?' 'Do these techniques and strategies really work?' Such questions routinely emerge from Western sceptics, unaware that they stem from the biomedical reductionism into which natives of Western culture have been socialized for almost a century now.

Efficacy is 'the perceived capacity of a given practice to affect sickness in some desirable way' (Young 1982:277). Actually, efficacy can mean any number of things ranging from total symptom reduction to some physical sign, like fever, emeses, or the like, which can be interpreted as a required proximate effect indicating that the ultimate anticipated outcome is on the way (Etkin 1988:301-302). From the perspective of medical anthropology, curing is efficacious when biomedical changes take place; healing is efficacious when the people who seek it say it is.

What is crucial to evaluating efficacy is understanding the cultural expectation and the biological outcomes at various stages of the therapeutic processes. Efficacy is always a cultural construct (Kleinman 1974a:210): 
The healing dialectic has been considered effective when the bonds between the sick individual and the group, weakened by disease, are strengthened, social values reaffirmed, and the notion of social order no longer threatened by illness and death; or when the individual experience of illness has been made meaningful, personal suffering shared, and the individual leaves the marginal situation of sickness and been reincorporated in health or even death back into the social body.

Medical anthropologists cannot totally explain how cultural factors are related to the healing process. There is more here than meets the biomedical eye. The best contemporary hypothesis is that the sick person in a specific context uses the semantic resources available and creates meaning. The meaning may be wholesome (placebo) or noxious (nocebo).

Moerman (1983) records the traditional wisdom on this point: 'meaning mends' and 'metaphor can heal'. Medical anthropologists note that placebo's mend when they are not understood to be that.

Metaphors heal best when they are taken literally and their symbolic identity is not recognized. When they are demystified they tend to lose their efficaciousness. In other words, healing boils down to meaning and the transformation of experience. The change or transformation is created by all participants who effectively enact culturally authorized interpretations. When demons are exorcised, the anxious client believes the cause of the problem is gone. This conviction is affirmed by the healer and encouraged by the social circle. It alters the client's cognitive processes from apprehension to calm.

'What has changed?' The life problems may or may not still be present, but their perception is no longer the same. 'Altered meanings exert practical efficacy in the felt experience of the patient' (Kleinman 1988:134).

\section{CONCLUSION}

Medical anthropologists believe that one advantage of ethnomedical and cross-cultural research is that the biomedical practitioner is forced out of a narrow professional orientation and exposed to aspects of human health that are frequently hidden by the role and social space the practitioner exercises in modern Western culture. Medical anthropology could work the same effect for the similarly specialized historical Jesus researcher. 
In traditional cultures it is not always possible to separate medicine from the religious system, as is routinely done in the West. Religion can be viewed as a cultural adaptive response to a much wider range of suffering and misfortune, of which human sickness is only a small part.

For this reason, Kleinman (1973:57) insists that 'without first possessing a fairly deep understanding of its cultural setting, it would seem impossible to understand a given system of medicine; this seems to hold as well for systems of scientificknowledge'. The historical Jesus researcher would thus move from a study of medical anthropology to the equally important study of Mediterranean anthropology. There is no other way to learn the concepts and values that govern and shape the understanding of healing in the first-century Eastern Mediterranean world.

What is the result? Medical anthropology, like all anthropological study, could help the exegete to adopt a transcultural stance, 'a perceptual stance and research posture that is detached or alienated but equidistant from two or more cultural units, however they may be defined' (Weidman 1988:261-262). One of these cultural units is the investigator's own.

From this position, the exegete could choose to become a 'culture broker' - that is, one who helps others understand cultures other than their own. The next step is to help others adopt a third culture rooted in expanded cross-cultural understanding. The process of developing a third culture entails first knowing one's own culture well, then recognizing the differences of the other culture. After learning to empathize with those differences, the exegete works at creating the common ground necessary for intercultural communication, that is, for answering the question: 'what does it mean for us'?

\section{Works consulted}

Caplan, A L H, Engelhardt, H T (Jr) \& McCartney J J (eds) 1981. Concepts of health and disease: Interdisciplinary perspective. Reading, MA: Addison-Wesley Publishing Company.

Cassell, E J 1976. Illness and disease. Hastings Center Report 6, 27-37.

Chrisman, N J \& Maretzki T W (eds) 1982. Clinically applied anthropology: Anthropologists in health science settings, in Culture, Illness, and Healing, Volume 5. Dordrecht: D Reidel Publishing Co.

Csordas, T J \& Kleinman A 1990. The therapeutic process, in Johnson and Sargent 1990:1-25.

Douglas, M 1966. Purity and danger. New York: Praeger. 1970. The healing rite. Man 5, 302-308.

Dow, J 1986. Universal aspects of symbolic healing: A theoretical synthesis. American anthropologist 88, 56-69. 
Draguns, J \& Harry T (eds) 1980. Handbook of cross-cultural psychology, Volume 6: Psychopathology. New Jersey: Allyn and Bacon.

Eisenberg, L 1977. Disease and illness: Distinctions between professional and popular ideas of sickness. Culture, Medicine and Psychiatry 1, 9-23.

Eisenberg, L \& Kleinman, A (eds) 1981. The relevance of social science for medicine. Dordrecht: D Reidel Publishing Company.

Engelhardt, H T (Jr) 1981. The concepts of health and disease, in Caplan et al 1981:30-35.

1986. The social meanings of illness. Second Opinion 1, 26-39.

Etkin, N L 1988 Cultural constructions of efficacy, in Van der Geest and Whyte 1988:299-320.

Fabrega, H 1971. The study of medical problems in preliterate settings. Yale Journal of Biology and Medicine 43, 385-407.

1974. Disease and social behavior: An interdisciplinary perspective. Cambridge and London: MIT Press.

Fitzpatrick, R 1984. Lay concepts of illness, in Fitzpatrick R, Hinton J, Newman S, Scambler G \& Thompson J (eds), The experience of illness, 11-31. London and New York: Tavistock Publishers.

Foster, G M 1976. Disease etiologies in non-Western medical systems. American Anthropologist 78, 773-782.

Foster, G M \& Anderson B 1978. Medical anthropology. New York: John Wiley.

Frank, J 1974. Persuasion and healing: A comparative study of psychotherapy. New York: Schocken Books.

Gaines, A D 1982. Knowledge and practice: Anthropological ideas and psychiatric service, in Chrisman and Maretzki 1982: 243-273.

Gaines, A D \& Farmer, P 1986. Visible saints: Social cynosures and dysphoria in the Mediterranean tradition. Culture, Medicine and Psychiatry 10, 295-330.

Gilmore, D D (ed) 1987. Honor and shame and the unity of the Mediterranean. Washington, D C: American Anihropological Association. (A special publication of the American Anthropological Association, Number 22.)

Gilmore, D D 1982. Anthropology of the Mediterranean area. Annual Review of Anthropology 11, 175-205.

Glick, L B 1967. Medicine as an ethnographic category: The Gimi of the New Guinea Highlands. Ethnology 6, 31-56.

Good, B \& Good, M, DelVecchio, Jo 1981. The meaning of symptoms: A cultural hermeneutic model of clinical practice, in Eisenberg and Kleinman 1981:165-196.

Good, B J 1977. The heart of what's the matter: The semantics of illness in Iran. Culture, Medicine and Psychiatry 1, 25-28. 
Grmek, M D 1989. Diseases in the ancient Greek world, translated by Muellner M \& Muellner L. Baltimore and London: The Johns Hopkins University Press.

Hahn, R A \& Kleinman, A M 1983. Biomedical practice and anthropological theory: Frameworks and directions. Annual Review of Anthropology 12, 305-333.

Harwood, A (ed) 1981. Ethnicity and medical care. Cambridge, MA and London: Harvard University Press.

Henderson, G 1989. Understanding indigenous and foreign cultures. Springfield, IL: Charles C Thomas.

Henderson, G \& Primeaux M 1981. Transcultural health care. Menlo Park, CA: Addison-Wesley Publishing Co.

Hill C E (ed) 1985. Training manual in medical anthropology. Washington, DC: American Anthropological Association.

Herzfeld, M 1986. Closure as cure: Tropes in the exploration of bodily and social disorder. Current Anthropology 27, 107-120.

Hughes, C C 1968. s v Ethnomedicine. International Encyclopedia of the Social Sciences. New York: Free Press.

Johnson, T M \& Sargent C M (eds) 1990. Medical anthropology: A handbook of theory and method. New York: Greenwood Press.

Kaplan, M 1983. A woman's view of DSM-III. American Psychologist July, 786-803.

Kleinman, A M 1973. Toward a comparative study of medical systems: An integrated approach to the study of the relationship of medicine and culture'. Science, Medicine, ana Man 1, 55-65.

1974a. Medicine's symbolic reality: On a central problem in the philosophy of medicine. Inquiry 16, 206-213.

1974b. Cognitive structures of traditional medical systems: Ordering, explaining, and interpreting the human experience of illness. Ethromedizin III, 27-49.

- 1978. Problems and prospects in comparative cross-cultural medical and psychiatric studies, in Kleinman ei al, Culture and healing in Asian societies 1978:407-440.

1980. Patients and healers in the context of culture. Berkeley: University of California.

- 1986. Concepts and a model for the comparison of medical systems, in Currer, C \& Stacey, M (eds), Concepts of health, illness and disease: A comparative perspective, 29-47. New York: Berg.

- 1988. Rethinking psychiatry: From cultural category to personal experience. New York and London: Free Press and Collier Macmillan Publishers.

Kleinman, A M \& Kunstadter, P E A \& Gate, J L (eds) 1978. Culture and healing in Asian societies: Anthropological, psychiatric, and public health studies. Cambridge, MA: Schenkman Publishing Co. 
Kleinman, A M \& Sung, L H 1979. Why do indigenous practitioners successfully heal? Social Science \& Medicine 13B, 7-26.

Landy, D (ed) 1977. Culture, disease and healing. New York: Macmillan.

Lewis, G 1981. Cultural influences on illness behavior: A medical anthropological approach, in Eisenberg and Kleinman 1981:151-162.

Lipowski, Z 1969. Psychosocial aspects of disease. Annals of Internal Medicine 71, 1197-1206.

Logan, M H \& Hunt, E E (eds) 1978. Health and the human condition: Perspectives on medical anthropology. North Scituate, MA: Duxbury Press.

Mackintosh, D R 1978. Systems of health care. Boulder, Co: Westview Press.

Mason, R C (Jr), Clark, G, Reeves, R R (Jr); Wagner, S B 1969. Acceptance and healing. Journal of Religion and Health 8, 123-142.

McElroy, A \& Townsend P K [1979] 1989. Medical anthropology in ecological perspective. Second Edition. San Francisco/London: Westview Press.

McGoldrick, M, Pearce, J K \& Giordano, J (eds) 1982. Ethnicity and family therapy. New York/London: The Guilford Press.

Mitchell, J C 1969. The concept and use of social networks, in Mitchell, J C, Social networks in urban situations, 1-50. Manchester: University Press.

Moerman, D E 1979. Anthropology of symbolic healing. Current Anthropology 20, 59-80.

1983. Physiology and symbols: The anthropological implications of the Placebo effect, in Romanucci-Ross et al 1983:156-167.

Morley, P 1978. Culture and the cognitive world of traditional medical beliefs: Some preliminary considerations, in Morley and Wallis 1978:1-18.

Morley, P \& Wallis, R (eds) 1978. Culture and curing: Anthropological perspectives on traditional medical beliefs and practices. Pittsburgh: University of Pittsburgh Press.

Murdock, G P 1980. Theories of illness: $A$ world survey. Pittsburgh: University of Pittsburgh.

Ohnuki-Tierney, E 1981. Illness and healing among the Sakhalin Ainu: A symbolic interpretation. Cambridge: University Press.

- 1984. Illness and culture in contemporary Japan: An anthropological view. Cambridge: University Press.

Palgi, P 1983. Mental health, traditional beliefs, and the moral order among Yemenite Jews in Israel, in Romanucci-Ross et al 1983:319-335.

Pfifferling, J-H 1981. A cultural prescription for medicocentrism, in Eisenberg and Kleinman 1981:197-222. 
Pilch, J J 1981. Biblical leprosy and body symbolism. Biblical Theology Bulletin 11, 119-133.

1985. Healing in Mark: A social science analysis. Biblical Theology Bulletin $15,142-150$.

1986. The health care system in Matthew: A social science analysis. Biblical Theology Bulletin 16, 102-106.

- 1988a. Interpreting Scripture: The social science method. The Bible Today 26, 13-19.

1988b. Understanding Biblical healing: Selecting the appropriate model. Biblical Theology Bulletin 18, 60-66.

1989a. Sickness and healing in Luke-Acts. The Bible Today 27, 21-28.

1989b. Reading Matthew anthropologically: Healing in cultural perspective. Listening: Journal of Religion and Culture 24, 278-289.

- 1991a. Sickness and healing in Luke-Acts, in Neyrey J H (ed), The social world of Luke-Acts, 181-209. Peabody, MA: Hendrickson.

1991b. Health in the New Testament: Did healings happen? National Outlook (Australia) 13/4, 12-14.

- 1991c. Introducing the cultural context of the New Testament. New York/ Mahwah: Paulist Press.

- 1992a Separating the sheep from the goats. PACE (Professional Approaches for Christian Educators) 21, 215-218.

- 1992b. A spirit named 'Fever'. PACE (Professional Approaches for Christian Educators) 21, 253-256.

1992c. BTB readers guide: Understanding healing in the social world of early Christianity. Biblical Theology Bulletin 22, 26-33.

Pilisuk, M \& Parks, S H 1986. The healing web: Social networks and human survival. Hanover, N H: U of New England Press.

Romanucci-Ross, L 1969. The hierarchy of resort in curative practices: The Admiralty Islands, Melanesia. Journal of Health and Social Behavior 10, 201-209.

Romanucci-Ross, L 1978. Melanesian medicine: Beyond culture to method, in Morley and Wallis 1978:115-138.

Romanucci-Ross, L, Moerman D E \& Tancredi L R (eds) 1983. The anthropology of medicine: From culture to method. New York: Praeger.

Saler, B 1977. Supernatural as a Western category'. Ethos 5, 21-33.

Saunders, L 1954. Cultural differences and medical care: The case of Spanish speaking people of the Southwest. New York: Sage.

Saunders, L \& Hewes, G 1969. Folk medicine and medical practice, in Lynch L R (ed), The cross-cultural approach to health behavior, 402-408. Rutherford, NJ: Farleigh Dickinson University Press. 
Scarborough, J 1969. Roman medicine. Ithaca: Cornell.

1988. Medicine, in Michael G \& Kitzinger R (eds), Civilization of the ancient Mediterranean, 1227-1248. New York: Charles Scribner's Sons.

Seymour-Smith, C 1986. s v Medical anthropology. Dictionary of Anthropology. Boston, MA: G K Hall \& Co.

Simons, R C \& Hughes, C C (eds) 1985. The culture-bound syndromes: Folk illnesses of psychiatric and anthropological interest. Dordrecht: D Reidel Publishing Co.

Spiegel, J 1982. An ecological model of ethnic families, in McGoldrick et al 1982:3151.

Turner, B S 1980. The body and religion: Towards an alliance of medical sociology and sociology of religion. The Annual Review of the Social Sciences of Religion 4, 247-284.

Turner, E, Blodgett, W, Kahona, S \& Benwa, F 1992. Experiencing riiual: A new interpretation of African healing. Philadelphia: University of Pennsylvania Press.

Twaddle, A C 1981. Sickness and the sickness career: Some implications in Eisenberg aid Kleinman 1981:111-133.

Unschuld, P U 1976. Western medicine and traditional healing systems: Competition, cooperation or integration? Ethics in Science \& Medicine 3, 1-20.

- 1980. The issue of structured coexistence of scientific and alternative medical systems: A comparison of East and West German legislation. Sorial Science and Medicine 14B, 15-24.

- 1988. Culture and pharmaceutics: Some epistemological observations on pharmacological systems in ancient Europe and medieval China, in Van der Geest and Whyte 1988:179-197.

Van der Geest, S \& Whyte, S (eds) 1988. The context of medicines in developing countries, in Studies in pharmaceutical anthropology. Dordrecht/Boston/London: Kluwer Academic Publishers.

1988. Pharmaceutical anthropology: Perspectives for research and application, in Van der Geest and Whyte 1988:329-369.

Weidman, H H 1982. Research strategies, structural alterations and clinically applied anthropology, in Chrisman and Maretzki 1982:201-241.

1988. A transcultural perspective on hea!th behavior, in Gochman, D S (ed), Health behavior: Emerging research perspectives, 261-280. New York and London: Plenum Press.

Wellin, E 1978. Theoretical orientation in medical anthropology: Change and continuity over the past half-century, in Logan and Hunt 1978:23-51.

Worsley, P 1982. Non-Western medical systems. Annual Review of Anthropology 11, 315-348. 
Young, A 1982. The anthropology of illness and sickness. Annual Review of Anthropology 11, 257-285.

Zborowski, M 1952. Cultural components in responses to pain. Journal of Social Issuès 8, 16-30.

1969 People in pain. San Francisco: Jossey-Bass.

Zola, I K 1966. Culture and symptoms: An analysis of patients: Presenting complaints. American Sociological Review 31, 615-630.

\section{Some Key Journals}

Medical Anthropology Quarterly - International Jourrial for the Cultural and Social Analysis of Health.

Official Journal of the Society for Medical Anthropology, published by the American Anthropological Association.

Medical Anthropology Newsletter to 1984; then succeeded by Medical Anthropology Quarterly.

Medical Anthropology, Cross-Cultural Studies in Health and Illness, published by Gordon and Breach Science Publishers.

Social Science and Medicine, includes articles by anthropologists, sociologists, geographers, economists, and other social scientists.

Ethnomedizin (Hamburg, Germany)

Culture, Medicine and Psychiatry

* This essay is a reworked version of the paper origirally published in SBL Seminar Papers (1993), Atlanta: Scholars Press, pp 154-177. HTS is granted permission to reprint the article. 